\title{
Anhang 5 \\ Die sieben Tafeln mit Karten aus dem „Magnetischen Atlas gehörig zum Magnetismus der Erde“ (Hansteen 1819)
}

Exemplar der Niedersächsischen Staats- und Universitätsbibliothek Göttingen, Sign. 2 PHYS III, 8480.

Da der „Magnetische Atlas“ von Hansteen eine Rarität und nur in wenigen Bibliotheken vorhanden ist, sollen hier alle in ihm enthaltenen Karten wiedergegeben werden. Am Ende der Monographie befinden sich farbige Abbildungen:

Abb. 48: Abweichungskarten für das Jahr 1600, 1700 und 1756.

Aus: Hansteen 1819, Tafel I.

Abb. 49: Abweichungskarten für das Jahr 1770, 1710, 1720 und 1730 sowie Neigungskarten für das Jahr 1700 und 1600 .

Aus: Hansteen 1819, Tafel II.

Abb. 50: Abweichungskarten für das Jahr 1800 und 1744.

Aus: Hansteen 1819, Tafel III.

Abb. 51: „Polar Projection eines Segments der Nördlichen und Südlichen Halbkugel, zur Aufklärung der Lage und Bewegung der Magnetpole vom Jahr 1600 bis 1800.“

Aus: Hansteen 1819, Tafel IV.

Abb. 52: „Karte der beyden Halbkugeln welche den Magnetischen Aequator und die Abweichungslinien für beyde Magnetaxen nach der ersten Eulerschen Theorie vorstellet.“

Aus: Hansteen 1819, Tafel V.

Abb. 53: „Mappa Hydrographica sistens Declinationes Magneticas anni 1787.“ Aus: Hansteen 1819, Tafel VI.

Abb. 54: „Mappa Hydrographica sistens Inclinationes Magneticas anni 1780.“ Aus: Hansteen 1819, Tafel VII. 